Fecha de recepción: marzo 2020 Fecha de aceptación: abril 2020 Versión final: junio 2020

\section{A las puertas de la Casa Rosada. La construcción del mundo imaginal kirchnerista (2003-2019) \\ Mariano Dagatti ${ }^{(1)}$}

Resumen: La política envuelve todos los sentidos: escuchamos, vemos, leemos discursos políticos, participamos en rituales políticos, asistimos a movilizaciones y protestas, recibimos la visita de un dirigente, seguimos las cuentas de líderes en las redes sociales digitales. Símbolos, imágenes, rituales participan de los mundos imaginales que las distintas fuerzas políticas pretenden desplegar como espacio de incorporación. Este artículo realiza una interpretación del mundo éthico del Frente de Todos en las elecciones nacionales de 2019. Para ello, recorre las lógicas imaginarias que el kirchnerismo desplegó desde su llegada al Poder Ejecutivo Nacional en 2003. Una hipótesis guía este texto: el mundo imaginal del actual gobierno representa una mutación respecto de aquel de la última década kirchnerista. Su fundamento es la recuperación de memorias asociadas con la cultura democrática y con la capacidad de gestión, memorias de valores y experiencias que la propia fuerza había impulsado en su origen y que después dejó progresivamente de lado.

Palabras clave: mundo imaginal - kirchnerismo - identidad nacional - democracia - competencia.

[Resúmenes en inglés y portugués en las páginas 157-158]

(1) Es Investigador Asistente del Consejo Nacional de Investigaciones Científicas y Técnicas (CONICET, Argentina). Ha obtenido los títulos de Doctor en Lingüística y de Magister en Análisis del Discurso por la Universidad de Buenos Aires. Su investigación actual, sobre construcción de hegemonía discursiva e identidades políticas en la Argentina contemporánea, está radicada en el Centro de Investigaciones sobre Economía y Sociedad en la Argentina contemporánea de la Universidad Nacional de Quilmes. Es profesor de Semiótica de Medios y Semiología en la Universidad de Buenos Aires. Ha publicado los libros El Partido de la Patria. Los discursos presidenciales de Néstor Kirchner (Editorial Biblos, 2017), De violencia, juicios y risas. Temas clásicos y contemporáneos de la Retórica (Asociación Argentina de Retórica, 2017), Los pueblos de la democracia. Política y medios en el siglo XXI (La Bicicleta Ediciones, 2018) y La vida por las ideas. Los discursos públicos de Néstor Kirchner (2006-2009) (EduViM, 2019). 


\section{Introducción}

En mi sentir prospera todo el que procede conforme a la condición de los tiempos, y se pierde el que hace lo contrario.

Nicolás Maquiavelo, El príncipe

Los hombres, en su proceder y mucho más en las acciones importantes, deben tener en cuenta los tiempos y acomodarse a ellos. Nicolás Maquiavelo, Discursos sobre la primera década de Tito Livio

"Nunca me desvelaron los cargos políticos, ni tampoco fueron mi principal motivación. Tal vez, porque pertenezco a una generación que no buscaba un lugar en las listas, sino un lugar en la historia". Con esa confesión comienzan las "reflexiones" y "decisiones"1 que la ex presidenta argentina Cristina Fernández de Kirchner compartió con sus "compatriotas" a través de un video el 18 de mayo de 2019 en su cuenta de Twitter. La confidencia inicial deja paso a la compresión histórica:

Sin embargo, también esa misma y por momentos trágica historia, me hizo comprender que los cargos también son herramientas para llevar adelante los ideales, las convicciones, las utopías. Es cierto que no las únicas, pero después de todo, son herramientas al fin, siempre.

La conclusión de este aprendizaje es conocido: la entonces senadora anuncia la fórmula Fernández - Fernández para competir en las elecciones presidenciales: "Le he pedido a Alberto Fernández que encabece la fórmula que integraremos juntos, él como candidato a Presidente y yo como candidata a Vice, para participar en las próximas elecciones primarias, abiertas, simultáneas y obligatorias... Sí, las famosas P.A.S.O.”.

La secuencia de argumentos que conduce del interés por un "lugar en la historia" al diseño de una fórmula presidencial distingue de manera explícita dos modos de pensar la política: en esas pocas palabras, una visión revolucionaria, inscripta en "un ethos de los setenta" ${ }^{2}$ caracterizado por la desconfianza en el sistema de partidos de la democracia, coexiste con una visión reformista, centrada en la transformación social dentro del marco de leyes, prácticas y normas ad usum de una democracia liberal ${ }^{3}$.

La conciliación de estas visiones históricamente en pugna a los fines de una decisión política es complementada por razones de índole personal ${ }^{4}$ :

Alberto, a quien conozco hace más de 20 años, y es cierto, con quien tuvimos también diferencias. Tan cierto como que fue Jefe de Gabinete de Néstor durante toda su presidencia... y lo vi, junto a él, decidir, organizar, acordar y buscar siempre la mayor amplitud posible del gobierno. 
Son las razones de una testigo privilegiada. La presentación de su compañero de fórmula concluye con un sintagma clave: "la mayor amplitud posible del gobierno". Decidir, organizar, acordar, buscar: la clave del gobierno por venir será -según la lectura de la ex mandataria- su capacidad para lograr una coalición amplia. Las virtudes políticas de Alberto Fernández -tácitas, sobreentendidas: experiencia de negociación, tolerancia, contención, conciliación- pueden sintetizarse en una sola palabra: gobernabilidad. Porque después de todo no se trata solo de ganar, sino de gobernar en medio de una situación crítica:

Sí... No tengo dudas. La situación del pueblo y del país es dramática. Y esta fórmula que proponemos, estoy convencida que es la que mejor expresa lo que en este momento de la Argentina se necesita para convocar a los más amplios sectores sociales y políticos, y económicos también, no sólo para ganar una elección, sino para gobernar. Porque algo le tiene que quedar claro a todos y a todas... Se va a tratar de tener que gobernar una Argentina otra vez en ruinas, con un pueblo otra vez empobrecido... Está claro, entonces, que la coalición que gobierne deberá ser más amplia que la que haya ganado las elecciones.

Con un tono ajeno a los vibratos que remedaban la voz de Eva Perón, las palabras de Cristina describen, sin embargo, una situación enfáticamente difícil. Por ello, la coalición debe volverse garante de que "aquello por lo que se convoca a la sociedad pueda ser cumplido". El mundo éthico de la competencia asoma como una red de contención simbólica ${ }^{5}$. La punta de ese iceberg es la figura de Alberto Fernández. Gobernar la Argentina que viene significa entonces -desde la perspectiva de la líder-conjugar el poder de movilización de su fuerza militante con las demandas de un liderazgo menos reacio a los acuerdos y matices, capaz de ejercitar sin sangrías mayores la tan denostada como necesaria "rosca" política".

Pero es preciso ir más allá: porque el video deja entrever una alteración del mundo imaginal del kirchnerismo, una búsqueda novedosa del ahora denominado Frente de Todos respecto de sus frustrantes experiencias electorales de 2013, 2015 y 2017. La derrota ofrece lecciones.

Nuestro artículo tiene por objetivo indagar el modo en que estas fueron interpretadas y ofrecer conclusiones preliminares sobre el mundo imaginal ${ }^{7}$ del Frente de Todos (en adelante, FdT). Un complejo de hipótesis guía este texto: este mundo representa una mutación respecto de aquel de la última década kirchnerista. Su fundamento es la recuperación de memorias asociadas con la cultura democrática y con la capacidad de gestión, memorias de valores y experiencias que la propia fuerza había en su origen impulsado y que había después progresivamente dejado de lado.

Pensar la configuración del mundo imaginal del FdT en las elecciones presidenciales de 2019 exige a nuestro entender una puesta en perspectiva, que permita estudiar una instancia actual en función de un conjunto de dinámicas previas. Por esa razón, el desarrollo de nuestro artículo está organizado con una perspectiva histórica; es, a su manera, una lectura del presente a partir de una lectura histórica, que me permitirá abordar de manera sistemática ciertas cuestiones que he trabajado a lo largo de los últimos diez años. La estructura del texto es la siguiente: en primer lugar, caracterizamos el mundo imaginal 
del primer kirchnerismo; después, exponemos los cambios que nos conducen a hablar de "segundo kirchnerismo"; en tercer lugar, a partir de un contraste de tipo sistémico, definimos las principales lógicas imaginarias de la coalición rival Cambiemos; por último, damos los primeros pasos en la caracterización del imaginario del FdT.

\section{Los mundos imaginales del kirchnerismo}

Conjeturar que la mutación de los imaginarios kirchneristas está definida simultáneamente por la coyuntura política y por la historia (imaginaria) de la propia fuerza nos conduce a un ejercicio doble. De un lado, indagar el estado del campo político en la Argentina contemporánea; del otro, estudiar las diferentes lógicas imaginarias que el kirchnerismo - en tanto eje de frentes o coaliciones más o menos amplias- desplegó sucesivamente como gobierno y como oposición. Dejaremos el estudio del presente para la sección final. Ahora nos centraremos en la historia imaginaria del kirchnerismo o, mejor dicho, en la historia de los imaginarios kirchneristas.

Con tal objetivo, en los apartados de esta sección inicial, trataremos de resumir los principales resultados de investigaciones previas acerca de los mundos éthicos desplegados por el Frente para la Victoria (en adelante, $\mathrm{FpV})^{8}$ desde su llegada al Poder Ejecutivo Nacional en 2003. La síntesis servirá para interpretar el mundo imaginal del FdT a la luz del devenir histórico de la fuerza.

Inicialmente, distinguiremos dos grandes momentos de la imaginación kirchnerista. El primero abarca la presidencia de Néstor Kirchner (2003-2007). Hablaremos ad hoc de "primer kirchnerismo". El segundo momento cubre las dos presidencias de Cristina Fernández y se extiende hasta la derrota de Unidad Ciudadana en las elecciones legislativas de 2017. Hablaremos de "segundo kirchnerismo" . A partir de esta distinción, y después de exponer nuestros argumentos, estaremos en condiciones de analizar finalmente el mundo imaginal del FdT.

Las conclusiones de nuestras investigaciones previas nos permiten afirmar que el mundo éthico del primer kirchnerismo resultó de la confluencia de una cultura nacional, de una cultura democrática y de un estilo de gobierno competente ${ }^{10}$. La idea, tantas veces expresada por Néstor Kirchner, de "capitalismo nacional" se orientaba en esa dirección. Pero si estos imaginarios y estilos de gestión dotaron al primer kirchnerismo de una imagen de gobernabilidad democrática, fue la primera, la cuestión nacional, devenida después nacional y popular ${ }^{11}$, la que le imprimió su sello indeleble, sobre todo de cara a la juventud ${ }^{12}$. Su singularidad como identidad política en la Argentina del siglo XXI. A nuestro entender, el peso de esta cuestión acabó por curvar las líneas del liberalismo democrático y de la competencia gubernamental. 


\section{El primer kirchnerismo: cuestión nacional, democracia y gobernabilidad}

Cuando asumió el cargo de presidente de la Nación, el patrio día del 25 de mayo de 2003, Kirchner convocó a "a todos y cada uno de los ciudadanos argentinos" a poner "mano a la obra de este trabajo de refundar la patria". El gesto fundacional tuvo espacio propio en un discurso inaugural que no prescindiría de "los testimonios de gestión y resultados" a la hora de mostrar sus credenciales:

Tenemos testimonio de gestión y resultados, somos parte de esta nueva generación de argentinos que en forma abierta y convocante y desde la propuesta de un modelo argentino de producción, trabajo y crecimiento sustentable, llama al conjunto social para sumar, no para dividir; para avanzar y no para retroceder. En síntesis, para ayudarnos mutuamente a construir una Argentina que nos contenga y que nos exprese como ciudadanos.

La crisis neoliberal exigía menos una declamación de las bondades de la patria que una garantía sobre la competencia gubernamental del nuevo gabinete. No olvidemos que el afiche más difundido para la campaña presidencial de 2003 tenía por eslogan: "Un país en serio", mientras que su spot principal decía:

Usted no lo conoce demasiado, porque es nuevo. No pertenece a la generación política del fracaso. Tomó su provincia muy endeudada, pagó, ahorró, y hoy Santa Cruz tiene el menor índice de desocupación y los más altos salarios de la Argentina. Tiene equipos, tiene planes, sabe gobernar. Anda tranquilo por la calle. Quiere a su familia. No miente. Hace lo que dice. Es tal como lo ves. Un día vamos a decir que con Kirchner pudimos mejorar el futuro de nuestros hijos. Los que seguimos amando a la Argentina construyamos con Kirchner esa Argentina que queremos.

Con el valor de lo nuevo como telón de fondo, la construcción del ethos de Néstor Kirchner como garante de "la Argentina que queremos" apelaba paralelamente a valores personales (franco, familiero, coherente, honesto) y a una experiencia de gestión ejecutiva ("Tomó su provincia muy endeudada..., "Tiene equipos, tiene planes, sabe gobernar"). La mención a los equipos técnicos no es casual: se trataba de demostrar competencia, es decir, recursos y experiencia para lograr los objetivos. Cuando terminaba el spot, la misma voz over que describía las virtudes del líder enunciaba:

Somos más de 1800 colaboradores, entre profesionales y voluntarios, trabajando durante más de dos años en cuarenta ciudades de toda la Argentina. Tenemos la radiografía más detallada y exhaustiva de todas las actividades productivas, administrativas, legales y financieras de nuestro país. Kirchner siempre dice: 'Es imposible administrar lo que no se conoce'. Durante la presidencia Kirchner todos vamos a notar la mejoría, pero sin ostentación. Vamos a trabajar tan silenciosamente como hasta ahora. 
Así como la ostentación de la austeridad, la demostración de competencia resultaría una dimensión central de la imagen del FpV como partido de gobierno. Aunque no todos los tópicos, no todos los valores alcanzan el mismo grado de interpelación, o acaso no lo conservan. Lo cierto es que el gobierno de Kirchner se presentaba en aquellos años como garante de una gestión competente orientada por la defensa de los intereses nacionales y de una cultura democrática, que habrían sido faro y guía de su generación.

\section{La cuestión nacional: el "soñar nación común"13}

El primer kirchnerismo apostaría por la reconstrucción de una identidad nacional que sintetizara -a su entender- los sueños de diferentes generaciones de argentinos, desde los revolucionarios de Mayo hasta los jóvenes militantes de los años setenta. Para ello, se presentó como legatario legítimo de una saga en la que no estaban ausentes ni las revoluciones patrias, ni las inmigraciones masivas de entre siglos, ni el peronismo como aglutinante social en torno a la cuestión nacional y popular, que su generación había intentado continuar ${ }^{14}$ :

Vengo, en cambio, a proponerles un sueño: reconstruir nuestra propia identidad como pueblo y como Nación; vengo a proponerles un sueño que es la construcción de la verdad y la Justicia; vengo a proponerles un sueño que es el de volver a tener una Argentina con todos y para todos. Les vengo a proponer que recordemos los sueños de nuestros patriotas fundadores y de nuestros abuelos inmigrantes y pioneros, de nuestra generación que puso todo y dejó todo pensando en un país de iguales. Pero sé y estoy convencido de que en esta simbiosis histórica vamos a encontrar el país que nos merecemos los argentinos (25 de mayo de 2003).

No sorprende por tanto que el principal colectivo de identificación de su imaginario político durante los años iniciales haya sido, de manera explícita o implícita, "nosotros, los argentinos". En un escenario de fragmentación y crisis de representación, el único partido posible era a los ojos de Kirchner "el Partido de la Patria". ${ }^{15}$ La axiología de ese «Frente de Todos» avant la lettre apostaba a un cúmulo de valores eufóricos que el kirchnerismo extraía de una cultura del trabajo enhebrada por industrias e inmigrantes. Honestidad, simpleza, humildad, esfuerzo:

Estoy dispuesto a avanzar con todas mis fuerzas en la defensa de los valores que nos lleven a consolidar de vuelta al país, a volver a hablar de patria, a volver a hablar de Argentina, a volver a hablar de nuestra bandera y del orgullo de ser argentinos, a recuperar la autoestima. Los argentinos somos gente que hemos construido nuestro prestigio con trabajo, esfuerzo y honestidad, y no por dos sinvergüenzas que nos vengan a confundir a todos... Es hora de la argentinidad, es hora de los argentinos (25 de octubre de 2004). 
Así definía el primer kirchnerismo el universo axiológico de la "nueva Argentina". Visto a la distancia, el objetivo era hilvanar entre las esquirlas de la crisis de 2001 una red identitaria nacional que habría sido el horizonte de sucesivas generaciones, postergado por la imposición del neoliberalismo. Este legado cimentaba así imaginariamente la reconstrucción posible y deseable de un "capitalismo nacional". La "hora de la argentinidad".

\section{La cultura democrática: pluralidad y verdades relativas}

El legado democrático constituyó una dimensión inescindible del primer kirchnerismo. Su presencia permitía destacar la preocupación gubernamental por inscribirse de manera provechosa en una matriz de sentido en la cual la reivindicación de un legado nacional no fuera interpretada como una conspiración contra las aspiraciones democráticas liberales (v.g. garantía de libertades públicas, división de poderes, tolerancia mutua, pluralismo, contención, respeto de las diferencias y voluntad de participación $)^{16}$. Ningún acto tuvo al respecto tanta relevancia como el Encuentro de la Militancia celebrado el 11 de marzo de 2004 en Parque Norte. Fue la coronación simbólica de la estrategia transversal del gobierno ${ }^{17}$. Allí Kirchner convocaría a "construir la verdad superadora que nos permita a todos los argentinos poder avanzar":

Los convoco a ustedes, pero través de ustedes a aquel argentino y argentina, a aquel trabajador y estudiante, a aquel que nos puede ver y escuchar a través de los distintos medios, que venga a trabajar, que abra el espacio donde crea, que practique la idea que quiera practicar, pero que se incorpore a esta Argentina donde con la idea, con el pensamiento, con la verdad relativa vamos a poder construir la verdad superadora que nos permita a todos los argentinos poder avanzar.

La disposición del primer kirchnerismo por presentarse como heredero legítimo de la cultura democrática constituye un acontecimiento que Sidicaro destacó tempranamente: Kirchner se "ha adaptado, saliéndose de la tradición populista, a una sociedad mucho más fragmentada y construida en términos de individuos. Eso es nuevo, es una ruptura con el discurso peronista. Hay elementos de la cultura peronista que están ahí, pero también incorpora una serie de temas diferentes. Básicamente, tiene que ver con reconciliar el liberalismo democrático con la tradición peronista. Es una novedad extraordinaria" (en Natanson, 2004, p. 40). Las menciones a los valores de una democracia plena, en este sentido, no iban a la zaga de las evocaciones de la saga nacional: la defensa del pluralismo, del consenso, de las verdades relativas y de la libertad de pensamiento coexistían con una ponderación de los movimientos populares y la cultura del trabajo, el contacto directo entre el líder y las masas y la reivindicación de "una Patria igualitaria".

Fueron las memorias del primer kirchnerismo en torno a la militancia juvenil las que ofrecieron las condiciones para articular, en torno a este colectivo generacional, los legados de una tradición nacional y de una tradición democrática. Este punto de vista 
generacional operó como el mecanismo discursivo encargado de organizar bajo una hermenéutica propia ciertas narraciones de los momentos fuertes de la tradición nacional con nociones como la pluralidad, la diversidad, el consenso, la diferencia y la libertad de pensamiento, que provenían de tradiciones heterogéneas, tales como el liberalismo democrático y el republicanismo. Las reivindicaciones de la identidad nacional y de la cultura democrática suturaban a su manera la disolución de los lazos comunitarios y la crisis de representación política que conformaron el diagnóstico que el primer kirchnerismo hizo de la situación argentina de la poscrisis.

\section{Gobernabilidad subliminal: el ethos de competencia}

Garante de una cultura nacional y democrática, el primer kirchnerismo diseñó imágenes de sí que generaron afecto social, como las del militante o el hombre común ${ }^{18}$. Pero la identificación -como el propio kirchnerismo experimentaría años después- no alcanza, también hace falta volverse digno de crédito ante el conjunto de la sociedad y aun ante los principales actores socioeconómicos.

Demostramos en una investigación anterior que el mundo éthico del primer kirchnerismo ofreció también imágenes de competencia, imágenes orientadas menos a seducir y movilizar que a garantizar y tranquilizar. Imágenes de competencia, en el sentido que Charaudeau las describe en Discurso político:

El ethos de competencia exige del orador saber y habilidad al mismo tiempo: debe tener un conocimiento profundo del dominio particular en el que ejerce su actividad, pero debe de igual forma probar que tiene los medios, el poder y la experiencia necesarios para llevar a cabo sus objetivos, logrando resultados positivos. Los políticos deben, por lo tanto, demostrar que conocen todos los engranajes de la vida política y que saben actuar de manera eficaz (2006, p. 125) ${ }^{19}$.

Realismo, racionalidad, capacidad de diagnóstico, planificación, coherencia, savoir-faire. El mundo éthico de la competencia prueba la constante preocupación gubernamental por certificar públicamente la viabilidad de su proyecto ante la sociedad argentina y fundamentalmente ante los principales actores socioeconómicos, en una situación de crisis política y económica. Así, en su discurso anual ante la Asamblea Legislativa, Kirchner expone su balance y su programa:

La más pura racionalidad indica que los argentinos deberemos afrontar grandes esfuerzos para salir del default y marca también que el camino de las viejas recetas está condenado al fracaso porque los recursos que somos capaces de generar hoy no pueden conformar a todos (1 de marzo de 2004)

"No se trata de ideologías (...) Se trata de una fría y racional lectura de los números y de la economía. Se trata de asumir con realismo lo que la situación indica” (1 de marzo de 2004). 
La experiencia social del primer kirchnerismo no estuvo ceñida a una imagen de renovación, acción y presencia permanente, garantizó también orden y previsibilidad. A nuestro entender, este ethos de competencia converge con los legados nacional y democrático, de modo tal de responder a la vez a "los dos movimientos más importantes del gran trastrocamiento de la escena política entre diciembre de 2001 y el final de la presidencia de Duhalde", según la intuición de Rinesi (en Natanson, 2004, pp. 19-22): un "movimiento conflictivista, contestatario, fuertemente antiestatal" y "una recuperación de una idea de orden". La verosimilitud del primer kirchnerismo se habría jugado -según su punto de vista- en la combinación de "un lado confrontativo" con "cierta entonación épica" y "una dimensión institucionalistaestatal" abonada a la "recuperación de la capacidad del Estado para dar sentido a la vida social".

A diferencia de las culturas nacional y democrática, la incorporación al mundo éthico de la competencia no puede lograrse más que en ejercicio de gobierno. Necesita demostración, insume una trayectoria, demanda un pasado: "Dijimos que íbamos a administrar el país ordenadamente y estamos haciendo una administración realmente equilibrada, como en cada gestión que me tocó llevar adelante", afirma Kirchner a menos de diez meses de su asunción (11 de marzo de 2004) ${ }^{20}$.Tiempo después, el escenario sería otro, radicalmente otro.

\section{La mutación kirchnerista: la apoteosis nacional y popular}

Catorce años después de la asunción de Néstor Kirchner, cuando compitió en 2017 por las elecciones legislativas bajo el sugerente nombre de Unidad Ciudadana, el mundo imaginal del kirchnerismo daba muestras de persistir en un tono que había adquirido progresivamente a partir de la primera presidencia de Cristina Fernández. Ese tono es el de un gobierno "nacional y popular" cuya imaginación está dominada por una fuerte impronta romántica. El sustrato antiliberal del peronismo había comenzado a permear todo el mundo imaginal ${ }^{21}$.

Aunque aquella campaña legislativa estuvo marcada por una discusión bizantina acerca de "la duranbarbización" de la ex presidenta (y del campo político en general)22, los gestos de apertura de la entonces senadora en términos de comunicación -nuevo tipo de puesta en escena en los actos políticos, entrevistas con periodistas afines y opositores- no terminaron de alterar una línea imaginaria que el kirchnerismo había elaborado paso a paso en la década anterior, notoriamente a partir del denominado "conflicto con el campo".

La mutación del mundo imaginal del kirchnerismo estuvo marcada -en términos de gestión- por la asunción de Cristina Fernández como presidente de la Nación, por la asunción de Néstor Kirchner como presidente del Partido Justicialista y por el alejamiento progresivo de algunos de sus principales funcionarios, dentro y fuera del peronismo. Los más notorios: Alberto Fernández, entonces jefe de Gabinete, en primer lugar; Sergio Massa, su reemplazante, en segundo lugar, un año después ${ }^{23}$. A fines de organización, hablaremos aquí del pasaje del "primer kirchnerismo»al «segundo kirchnerismo».

Si durante la administración de Néstor Kirchner, el primer kirchnerismo reivindicaría 
la defensa de una identidad nacional y de una cultura democrática, del mismo modo que garantizaría capacidad de gobierno, el mundo imaginal del segundo kirchnerismo privilegiará progresivamente $-\mathrm{y}$ de manera decisiva después de la holgada victoria en las elecciones presidenciales de 2011- una identidad "nacional y popular», regida por un modelo erístico de tratamiento de los asuntos públicos. El éxito en la disputa, el ejercicio del conflicto y el vilipendio ante las objeciones del adversario o del indiferente se convirtieron en un método privilegiado de producción de su verdad política. La contención y la tolerancia perdieron terreno - desde un punto de vista liberal- ${ }^{24}$.

Ciertamente, a partir del bienio 2007-2008, la mutación estuvo ligada a un desplazamiento fundamental en la relación del FpV con el peronismo. Hasta entonces apenas celebrado y más bien disimulado, este se vuelve explícito como "columna vertebral" del frente "nacional y popular". Hay un "regreso pleno al peronismo" (Curia, 2010, p. 28). La inscripción del kirchnerismo en una posición enunciativa generacional ("nosotros, la generación de los setenta”), que le había permitido desdibujar las filiaciones partidarias en provecho de una filiación etaria y convocar a amplios sectores y actores de la vida nacional, debía ser interpretada ahora como la pertenencia a una vanguardia política en la que los herederos de Perón y Evita luchan junto al pueblo contra la opresión de las elites locales y foráneas.

El espacio de los adversarios emergió en esta lógica erística de manera implacable: la ostentación de la representación del peronismo como eje de un frente nacional y popular fue paralelo a la construcción de una instancia adversativa de índole político-mediática. No se trataba de una faceta antes inexplorada: la dimensión polémica o adversativa había estado presente en el FpV desde el primer día de gobierno. Pero se trataba de un conflicto con el pasado: con el papel de los políticos, de las Fuerzas Armadas, de la Iglesia, de los medios de comunicación durante la larga noche neoliberal que había comenzado con la dictadura. La frontera era eminentemente temporal. A partir de 2007-2008, el tiempo de la frontera se conjugó en presente: la oposición, las corporaciones mediáticas (el multimedio Clarín pasó de aliado a principal rival), las elites (sobre todo, la agropecuaria) y progresivamente los otros poderes del Estado, sobre todo el Poder Judicial.

Así las cosas, el mundo imaginal del segundo kirchnerismo se definió por una celebración de ciertos valores o símbolos considerados trascendentales como la patria o la nación, por la reivindicación de las causas del pueblo, entendido como colectivo y demandante soberano, por la bendición de los liderazgos carismáticos. Las convicciones, el coraje, la voluntad permearon todo el espacio de gestión. A menudo se ofrecía de la política una visión tan colectiva y multitudinaria como jerárquica; en este sentido, los encuadres de sus filmaciones o de sus afiches parecen conminados a la panorámica o al plano cenital (Figuras 2 y 3). El mundo imaginal del segundo kirchnerismo apeló a formas de imaginar la política que tuvieron una intensa vida en el siglo XX y de las cuales no escaparon movimientos tan diversos como el fascismo italiano o el socialismo francés o, en la Argentina, el radicalismo, el comunismo y el peronismo. 


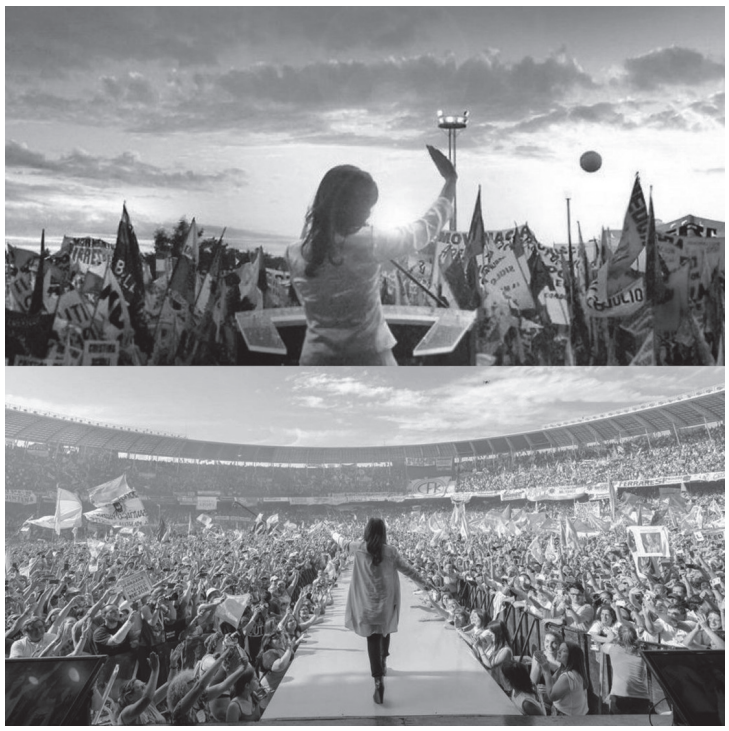

Figura 1. Cristina y las multitudes. Fuente: Elaboración propia con base en Blog No me quiero olvidar. Disponible en: https:// nomequieroolvidar.wordpress. com/2011/10/27/afichescristina-2011/cristina2011/ y Diario El País. Disponible en: https://elpais. com/internacional/2017/10/15/ argentina/1508091946_968020.html

Sus rituales públicos preferidos apostaban a las multitudes y envolvían, por lo general, una condición épica, con una fuerte carga adversativa: eran verdaderos "rituales de enfrentamiento", si tomamos la aserción de Abélès (2017). La política era imaginada como una praxis intensa, apoteósica. Se trataba -recordemos algunas frases muy escuchadas o leídas- de "dejar la vida por la política", de "insistir ante la adversidad", "de no renunciar a las ideas", de imaginarse la política dominada por esa "tiranía del ideal” de la que hablaba Barthes (2003). El mundo imaginal del segundo kirchnerismo se alimentó de una ética de la hiper-politización: la política implicaba una praxis extraordinaria, cuyos contornos respecto a la vida cotidiana, a los hábitos y a las costumbres aparecían a menudo tallados con pulso firme. Así, subordinaba o relegaba la representación política de los espacios privados, considerados secundarios o ajenos respecto de las dinámicas políticas; incluso en las redes sociales digitales, en las que la exposición de lo privado es regla y no excepción. En suma, la tonalidad nacional y popular permeó todo el mundo imaginal del kirchnerismo, de modo que los matices imaginales de la democracia y de la competencia gubernamental se fueron diluyendo ${ }^{25}$.

\section{Por qué los imaginarios importan: el triunfo de Cambiemos}

Las elecciones de 2015 confirmaron una tendencia de las elecciones de 2013: el kirchnerismo había perdido su sintonía fina con el espíritu de época. Las razones fueron múlti- 
ples, esbozamos algunas de ellas en las páginas precedentes. Creemos que la primacía de un rostro nacional y popular es una respuesta posible, si tenemos en cuenta que el FpV había demostrado en sus inicios capacidad lectora y porosidad ideológica para articular demandas concretas y simbólicas de amplios sectores de la sociedad argentina.

No se gobierna durante doce años sin desgaste. El kirchnerismo perdió gran parte de su capacidad de articulación de demandas en ese lapso; o, dicho de otra forma, elaboró un set de demandas más homogéneas. Los días finales del mandato de Cristina Fernández mostraron a un kirchnerismo renuente a tomar una medida que no se presentase como un paso adelante del pueblo y un retroceso de las corporaciones enemigas. La victoria de Cambiemos, que consiguió votos en sectores y territorios donde el mundo imaginal del peronismo tuvo a lo largo de la historia gran parte de su eficacia, nos exige pensar qué sucedió.

Las elecciones de 2015 manifestaron prima facie las consecuencias negativas de ese «síndrome de permeabilidad imaginaria». A menudo los tiempos electorales constituyen una competencia entre diferentes posiciones - ergo, imaginarios, espacios, identidades- dentro del sistema topológico ${ }^{26}$ del campo político. Ni en 2005, 2007, ni en 2009, ni en 2011, ni en 2013; en ninguna de las elecciones previas de las que había participado el FpV como partido de gobierno, una fuerza opositora había logrado construir acabadamente -más allá de ganar o a menudo perder- un mundo imaginal alternativo, que ofreciera la utopía de una Argentina otra ${ }^{2}$. Cambiemos-Pro fue la primera en hacerlo.

\section{La utopía de la Argentina moderna}

Cuando Mauricio Macri, líder de la coalición Cambiemos ${ }^{28}$, brindó, en su condición de Presidente de la Nación, sus discursos ante la Asamblea Legislativa, la respuesta a la pregunta por qué había sido el kirchnerismo, que tantas y tan dispares había generado en los años precedentes y seguía aún generando al calor de los balances de los diferentes actores políticos, sociales y mediáticos, no dejó lugar para las medias tintas ni para matices sugerentes: en su visión, fue un proyecto de "autoritarismo irreversible"; una gestión "irresponsable", "incompetente", que diseñó un Estado "plagado de clientelismo, de despilfarro y corrupción” (1 de marzo de 2017).

El gesto inaugural de Cambiemos estableció un rechazo frontal de la gestión anterior, cuya "pesada herencia" se traducía, de acuerdo con los argumentos del mandatario, en haber hipotecado el futuro en nombre de un presente irracional: "Basta de que nos regalen el presente para robarnos el futuro" (1 de marzo de 2017). Esta hipoteca habría tenido por efectos el perjuicio de los argentinos en general y de los sectores marginales en especial, a la vez que habría demostrado el papel del kirchnerismo como fuente del mal, avatar postrero del populismo vernáculo.

Según sus propios voceros e ideólogos, Cambiemos avanzó por los senderos de constitución de "una Argentina moderna" cuyo ingreso al siglo XXI se habría visto retrasado por una gestión infausta que ahora, desde el llano, se revelaba en su cruda y vetusta verdad. La "Argentina del Siglo XXI" implicaba un rechazo conceptual del pasado en nombre de 
una generación joven, adaptada a los nuevos tiempos de la globalización 2.0. Esta inclinación hacia el futuro favorecía diferentes estrategias, una de ellas aquí central: conseguía impugnar al kirchnerismo no sólo como un populismo cleptómano, sino, sobre todo, como representante principal de formas perimidas de hacer política: la de los "liderazgos mesiánicos", la del "sistema arcaico" de voto, la de un país que ve al mundo como una "amenaza" (todas citas del discurso del 1 de marzo de 2017).

A nuestro entender, esta cuestión es fundamental, porque deja entrever el clivaje de los imaginarios en pugna. Durante la campaña electoral de 2015, el mundo imaginal de Cambiemos estuvo marcado por una imaginación de la política en la que esta se revelaba como un asunto cotidiano, próximo, cercano. La imaginación política de Cambiemos escapaba a las multitudes. "Y cuando les digo que trabajamos en serio para construir las bases de crecimiento, hablo de esto, de algo tan básico como abrir una canilla y que salga agua limpia": esta frase, que pronunciara en su tercer discurso anual ante la Asamblea Legislativa (1 de marzo de 2018), es un ejemplo, pero también un modelo. Los efectos de la política no se deben percibir más que en los beneficios diarios de aprehensión individual, familiar o a lo sumo vecinal. Hacer una ruta es ganar tiempo de tu vida, instalar wi-fi en las plazas es mejorar tu conexión.

No sorprende entonces que los espacios representados en sus spots o afiches sean las casas (preferentemente humildes), las plazas (espacio vecinal por excelencia), los clubes, las pequeñas y medianas empresas (el paradigma es aquí un kiosko o una lencería). Con Tönnies (1947), podríamos decir que prevalece una idea de comunidad: vida familiar, negocios de barrio, vecinos y vecinales. La relación entre los representantes y los representados se pretende mano a mano: una visión agregativa, individual y conectiva de la política.

Timbreos, llamados telefónicos, emails: "Hola, soy Mauricio Macri y quería invitarte a...”. El voseo complementa el trato: "Estoy con vos" era más que la canción de una campaña electoral en 2015, era una hipótesis de contacto, que apostaba a borrar la distancia. Las conferencias de prensa, las entrevistas, la desestimación de las Cadenas Nacionales dejaban ver un énfasis en géneros dialógicos de la puesta en escena, que de ninguna manera obturaban la existencia, por lo demás esperable, de géneros monológicos, como el discurso anual del presidente ante la Asamblea Legislativa. La escucha era un elemento esencial, una marca: en el mundo de Cambiemos, si los líderes autoritarios hablan (Castro, Chávez y, claro, Cristina), los líderes próximos escuchan.

\section{Las lógicas imaginarias del gobierno de Cambiemos}

Los tiempos electorales son momentos en los que la imaginación está subordinada a la competencia: imaginar es allí netamente seducir. Convocar a los indecisos. Los tiempos de gobierno son otros: continuos, permanentes, aun cuando cada dos años uno y otro se superpongan.

El contraste del mundo éthico de Cambiemos con la apoteosis popular del segundo kirchnerismo alcanzaría un desarrollo sostenido durante la gestión de Macri. Como gobierno 
nacional, Cambiemos desplegó diferentes lógicas imaginarias en torno a la gestión y a la política, lógicas que excedieron -sin traicionar ni negar- el mundo imaginal de la proximidad y la cotidianidad que había alentado durante la campaña. En los años recientes nos abocamos a describir las principales ${ }^{29}$ : la lógica del gobierno próximo, la lógica del Estado-máquina, la lógica del gobierno transparente, la lógica del gobierno pastoral y la lógica del gobierno protocolo. No tenemos aquí el espacio para caracterizar in extenso cada una de ellas. Solo diremos cuestiones básicas a los fines de la argumentación que sigue.

La lógica del gobierno próximo apuesta a una política de relación asidua, frecuente, cotidiana, amistosa. Estar en contacto, en diálogo, chequear la vigencia del canal de comunicación con los ciudadanos. Sus valores centrales son la escucha, la falibilidad, la cercanía. La ecología de los medios conectivos contribuye, en un sentido, al despliegue de esta lógica, en tanto se producía una ampliación de los imaginarios políticos por adaptación a las memorias discursiva, comunicacional y semiótica de las prácticas de comunicación digital (enviar mails, postear, pero sobre todo darle visibilidad pública a los tonos y tópicos de las esferas privada e íntima) (Figura 2).
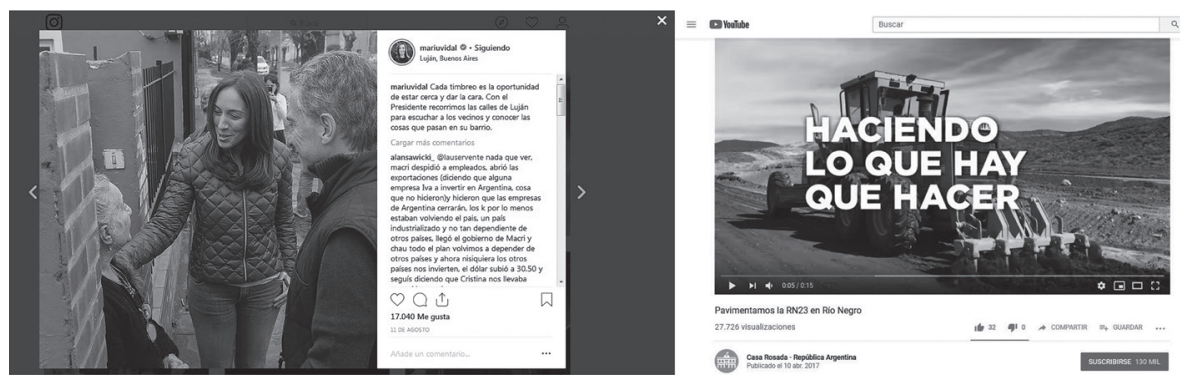

Figura 2. Timbreo y obra pública. Fuente: Elaboración propia con base en tuit de María Eugenia Vidal y publicación del canal You Tube de Casa Rosada. Disponibles, respectivamente, en: https://twitter.com/ mariuvidal/status/1028347935032045568?lang=es y en: https://www.youtube.com/watch? $\mathrm{v}=\mathrm{AEaONEc}$ JGQ

La lógica del Estado-máquina remite a una dinámica basada en la eficiencia, inspirada en una cierta deontología ajena a la voluntad o el deseo subjetivo: "Haciendo lo que hay que hacer" es el slogan de una serie de audiovisuales y afiches que nos sugieren, mediante la argumentación por el ejemplo, que el paroxismo de gobernar es hacer. Se juega en esta lógica una suerte de reivindicación de la obra pública como deber estatal más allá de todo agente político responsable. El largo plazo de la obra pública -la intemporalidad del Estado- contrasta en Cambiemos, como de costumbre, con el corto plazo del populismo. Al mismo tiempo, la trascendencia de la acción pública no carece de un carácter doméstico, 
próximo, hogareño: la red de agua y abrir una canilla. Eficiencia, trascendencia y tangibilidad de la obra pública son elementos claves (Figura 2).

Mientras tanto, la lógica del gobierno pastoral remite a dos dinámicas complementarias, que llamamos totalizante e individualizante. El colectivo y el individuo, y en el medio una suerte de circulación irrestricta de las voces de todos y cada uno de los ciudadanos, facilitada por la coordinación de la dirigencia política. La clave es la preocupación por todos, como colectivo nacional, y por cada uno, valorado en su estricta condición de individuo. De un lado, afiches o spots con frases como "Todo es posible juntos"; del otro, e-mails con un saludo individualizante: "Hola, Mariano...". La capacidad de gestión de datos del denominado "liberalismo digital" facilita esta búsqueda y sus resultamos: estamos en el terreno de lo que Sadin (2018, p. 148) denomina el management algorítmico de la industria de la vida, que apuntaría a una "automatización personalizada de la gestión de nuestras necesidades" (Figura 3).

Cuando hablamos de lógica del gobierno transparente nos referimos a una suerte de adaptación imaginaria ante el constante ejercicio ciudadano de vigilancia y denuncia. ${ }^{30}$ Informar sobre obras, publicar la agenda, difundir sobre el uso del presupuesto, brindar acceso -o facilitarlo- al estado de las cuentas públicas, etc. (Figura 3). La quinta lógica es la del gobierno protocolo, que consiste básicamente en mostrar actividades protocolares de los funcionarios públicos (notoriamente, el presidente y su gabinete): reunión con Jefes de Estados o ministros, encuentros con empresarios, inauguraciones de obras, y un largo etcétera asociado a los menesteres propios del gobierno. Es otro modo de poner en escena el diálogo y de reivindicar el valor de las instituciones (Figura 3).

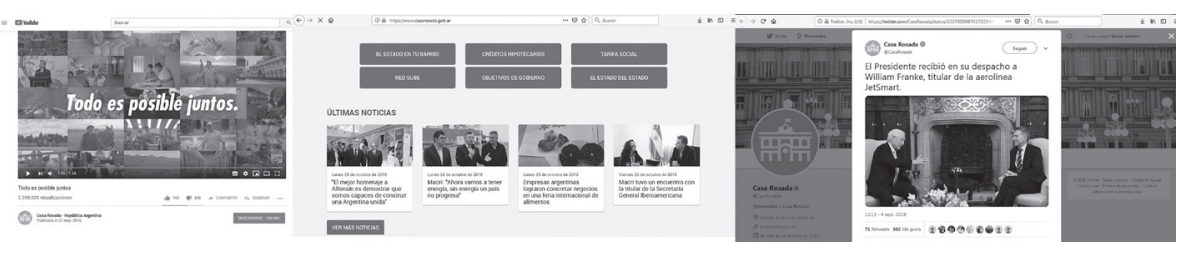

Figura 3. Casa Rosada. Fuente: Elaboración propia con base en Canal You Tube de Casa Rosada, sitio web de la Casa Rosada y Cuenta de Twitter de la Casa Rosada. Disponible, respectivamente, en: https:// www.youtube.com/watch?v=Pkg2uWOWTF4\&t=1s, https://www.casarosada.gob.ar/ y https://twitter. com/CasaRosada/status/1037055987017023496

Cada una de estas lógicas hizo las veces de antídoto contra los denunciados males del populismo kirchnerista -e incluso, contra las formas perimidas de hacer política-. Dirigentes próximos que construyen una relación de calidad, cuasi simétrica, opuestos a dirigentes "mesiánicos" que privilegian una relación cuantitativa y asimétrica; un gobierno eficiente y preocupado por el largo plazo contra gobiernos ineficientes, preocupados por 
el presente; un gobierno transparente contra un gobierno corrupto; un gobierno sensible a los individuos frente a gobiernos de masas; un gobierno republicano, democrático, respetuoso de las instituciones enfrentado a un gobierno populista, autoritario, incapaz de practicar la tolerancia y la contención, destinado a convertir la Argentina en Venezuela. La famosa "grieta" se construyó también sobre la base de estas dicotomías impermeables.

\section{De los Kirchner a los Fernández: memorias de la supervivencia}

El mundo imaginal del FdT dialoga en las elecciones presidenciales recientes no sólo con la coyuntura histórica, unánimemente considerada crítica por opositores y oficialismo, sino también con el pasado del propio kirchnerismo como espacio político. Comenzamos este artículo con una descripción del mundo imaginal del primer kirchnerismo; después ofrecimos una síntesis de los cambios que caracterizaron el pasaje del primer al segundo kirchnerismo y enseguida expusimos los problemas de su deriva nacional y popular. El surgimiento de un mundo imaginal alternativo nos permitió contrastar las dinámicas en pugna, atender el sistema topológico a partir de los imaginarios. Ahora veremos qué ha quedado en 2019 de estos mundos y trataremos de explicar -aunque sea de manera provisoria- las razones.

Iniciemos este tramo final con Cambiemos. La coalición ahora denominada Juntos por el cambio (JxC) continuó -hasta que la victoria se presentó improbable, sino imposible $e^{31}$ - con una estrategia comunicacional parecida a la que le había dado sus frutos en las dos elecciones nacionales anteriores $(2015 \text { y } 2017)^{32}$. Sin dejar de lado la apuesta a un ethos de proximidad y a una suerte de ethos de competencia potencial -ipero cómo se demuestra competencia sino en presente!-, el acento estuvo puesto en la obra pública y en el fantasma del regreso del autoritarismo kirchnerista. No hubo aquí, como antes, espacio nítido para la utopía de una Argentina moderna; apenas pruebas de las obras públicas ejecutadas (o en curso) y advertencias sobre el populismo por venir. Como Scioli en 2015, agitar el miedo opacó las luces del futuro: la utopía quedaba del otro lado.

No tenemos espacio para un desarrollo sistemático. Nuestros argumentos se servirán entonces de ejemplos considerados paradigmáticos. Tomemos el spot de JxC “ ¿Vos, querés volver?", que sintetiza estas cuestiones. Un montaje alternado muestra el antes y el después de lugares donde el gobierno realizó obras públicas (Paseo del Bajo, Viaducto Belgrano, Metrobús, rutas nacionales, terminales de transbordo, etc.). El antes remite a la gestión de los Kirchner; el después, a la gestión de Cambiemos. La banda de imágenes está acompañada por el audio de otro video que semanas atrás se había vuelto viral, en el que militantes kirchneristas le cantan a un Macri atónito: “¡A volver, a volver, vamos a volver!”, cántico típico de la militancia kirchnerista después de la derrota en 2015. La escena transcurre en Suiza, durante la visita del entonces presidente a la cumbre de Davos. Por un lado, las imágenes que prueban las obras de un gobierno en apariencia competente; por el otro, las voces que ejemplifican la intolerancia de los adversarios (Figura 4). 


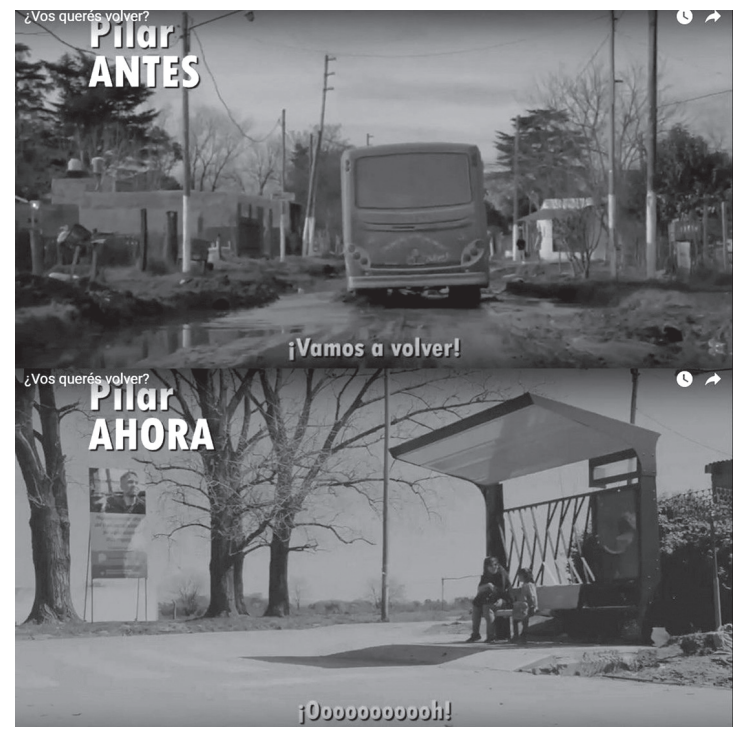

Figura 4. “¿Vos, querés volver?” Pilar antes / Pilar ahora. Fuente: Agencia DIB. Disponible en: https://www.youtube.com/ watch?v=CqahlT7PwnA

No hubo mucho más. Si en 2015 Cambiemos tuvo la iniciativa discursiva -recordemos el debate presidencial del balotaje entre Scioli y $\mathrm{Macri}^{33}$-, en 2019 las grandes novedades en términos de imaginación política corrieron por cuenta del FdT. Desde los spots de Alberto Fernández y Axel Kicillof hasta los flash-mobs en diferentes puntos del país. ${ }^{34} \mathrm{El}$ fantasma del autoritarismo no hizo demasiada mella ante una campaña centrada menos en la figura de Cristina que en la del candidato presidencial. Esta prevalencia de Alberto es la cifra de una estrategia más amplia, pero, sobre todo,-conjeturamos- de una mutación de los imaginarios que el FdT convocó a la hora de competir electoralmente.

Nuestra hipótesis es que esta mutación significó grosso modo una vuelta al mundo imaginal del primer kirchnerismo. Una vuelta que no implicó necesariamente olvidar el rostro "nacional y popular", pero sí difuminarlo en memorias menos confrontativas. En términos de campaña electoral, la razón parece haber sido el "techo" electoral de la líder y las rispideces que generaba en ciertos sectores del peronismo y del progresismo para una eventual coalición ${ }^{35}$. Ahora bien, nos interesa avanzar más allá de las estrategias y analizar qué mundo imaginal construyó el FdT y cuáles parecen haber sido las razones discursivas desde un punto de vista topológico.

La campaña del FdT estuvo en los hechos desdoblada. Cristina Fernández recorrió buena parte del país con el fin de presentar su libro Sinceramente -una suerte de autobiografía de gestión-. El formato "presentación de libro" ocupó el lugar de los rituales multitudinarios y confrontativos, aun cuando los argumentos estuvieran destinados a fidelizar su $30 \%$ de electores. En cambio, Alberto Fernández estuvo abocado a la tarea de abrir el frente y convocar al resto del peronismo y al electorado indeciso. Para ello, activó memo- 
rias marginadas del kirchnerismo, que éste había desplegado antes como espacio político y como partido de gobierno. Por un lado, puso en el centro de la escena -como había sucedido sobre todo en el bienio 2003-2005- valores caros al liberalismo democrático: tolerancia, pluralidad, apertura, diálogo, contención. Apostó, por decirlo así, a disolver el sustrato antiliberal del imaginario kirchnerista. Por otro lado, en una situación de crisis, trajo a colación el mundo éthico de la competencia: la capacidad, ya demostrada, para gobernar en una emergencia ${ }^{36}$.

No se puede desconocer que estas memorias de la democracia y la competencia gubernamental encontraron en la figura de Alberto Fernández un garante idóneo. Consideraré a modo de ejemplo una pieza central: el spot de presentación de su candidatura a presidente, lanzado en redes el sábado 6 de julio de 2019, un día antes de que comience oficialmente la campaña electoral (Figura 5).

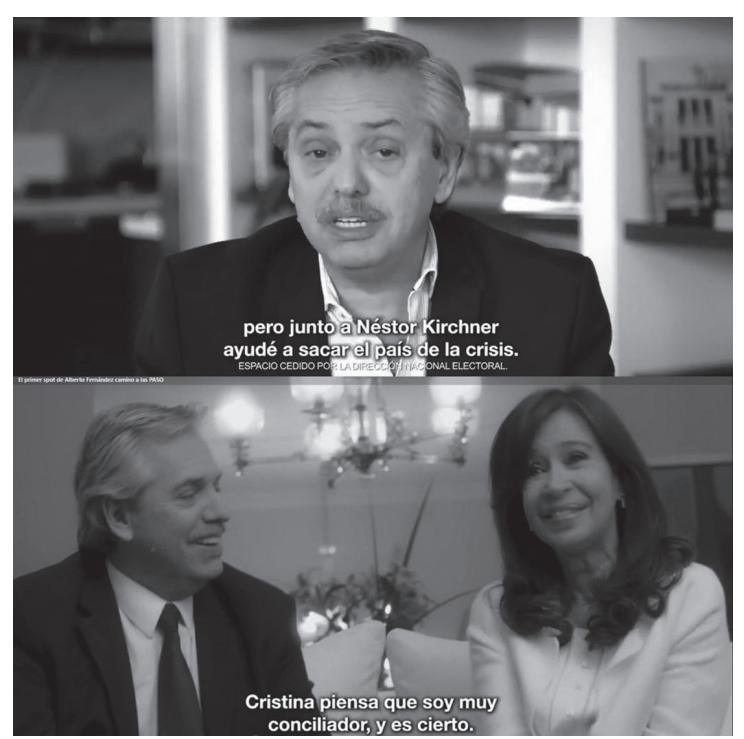

Figura 5. Spot de Alberto Fernández. Fuente: Timing político. Disponible en: https://www.youtube.com/ watch?v=weLeOZZJbDU

Todo el foco del video está puesto en la figura de Fernández, las referencias a Cristina son mínimas (tanto verbal como visualmente). Pese a tratarse de un gesto codificado, la pose, la mirada a cámara y el plan de texto recuerdan el spot de Kirchner en la campaña presidencial de 2003. Como aquel, también este comienza con un presupuesto: el desconocimiento del candidato. En el inicio, Alberto se presenta: "Quizás no lo recuerdes, pero junto a Néstor Kirchner ayudé a sacar al país de la crisis”. A esta primera entrada, le sigue, como aquella vez, la construcción de un ethos: 
Cuando no estoy de acuerdo en algo digo que no. Cristina piensa que soy muy conciliador, y es cierto. Pero cuando es necesario sé poner las cosas en su lugar. Soy profesor de la UBA, fana del Bicho, y me gusta pasear a Dylan [su perro]. Soy un tipo común. Quizás por eso es que puedo entender tus problemas.

La imagen del hombre común -capaz de comprender los problemas de los argentinos porque es como ellos- convive con la de un candidato no autoritario, democrático: firme, pero conciliador. El ethos dicho deja paso al tramo final, que se organiza en torno al tópico de una crisis evidente y su solución: "Hoy soy candidato a presidente y, junto a Cristina. voy a ordenar el caos que nos están dejando. Tenemos la fuerza para hacerlo. Hay futuro para vos. Hay futuro para todos". El tópico fundacional -sin tonos épicos, no obstante- abre el tiempo de la esperanza.

\section{Conclusiones: las memorias de un frente para gobernar}

Comenzamos este artículo con citas del video en el que la ex presidenta anuncia la fórmula Fernández - Fernández para competir en las elecciones presidenciales. Ese video marca a mi entender el primer hito de la mutación imaginaria del FdT: sin tonos altisonantes ni panorámicas multitudinarias, la pieza está orientada a exponer las razones de una decisión política. Estas remiten a la capacidad de gobierno, a la experiencia, a la responsabilidad, a la aptitud para lograr "la mayor amplitud posible de gobierno". Terminamos el recorrido por los mundos imaginales del kirchnerismo -y cuando fue necesario, de su principal adversario- con el primer spot de Alberto Fernández durante la campaña de las primarias nacionales. Señalamos allí la construcción de un mundo éthico teñido por la proximidad, la conciliación, la capacidad de gestión.

Intentamos identificar las razones de estas estrategias políticas a lo largo de tres grandes secciones. La primera estuvo centrada en el mundo imaginal del primer kirchnerismo. Expusimos las conclusiones de investigaciones previas en las que demostrábamos que a partir de una inscripción generacional el gobierno procuraba conciliar las tradicionales nacional y democrática liberal, ofreciendo un mundo de valores donde el carisma del líder no iba en desmedro de las verdades relativas y la pluralidad de ideas. El primer kirchnerismo demostró asimismo capacidad de gobierno en una situación crítica, que le reportó credibilidad ante el conjunto social y específicamente ante los actores socioeconómicos preponderantes. Hablamos al respecto de un ethos de competencia. La segunda sección consideró la mutación del mundo imaginal del kirchnerismo a partir de la progresiva prevalencia del imaginario nacional y popular, paralela a la retracción del imaginario liberal. Argumentamos que este cambio en el orden imaginario redundó en una incapacidad creciente para articular demandas de diferentes actores sociales. Una fuerza de centro-derecha, Cambiemos, consiguió ganar en las elecciones presidenciales de 2015 proponiendo otro horizonte político, la de "una Argentina moderna", "una Argentina del siglo XXI". A la democracia de alta intensidad, le opuso un mundo imaginal donde la política es próxima, tangible, práctica, ajena a los conflictos y centrada en 
el diálogo, la escucha y el consenso. Esa fue su utopía. Dedicamos una tercera sección a analizarla. Teniendo en cuenta el devenir del kirchnerismo, conjeturamos por último algunas hipótesis acerca del mundo imaginal del FdT. A nuestro modo de ver, este colocó en el centro de su imaginación memorias que eran las suyas y que habían sido progresivamente marginadas: el saber gobernar, la cultura democrática, la capacidad de diálogo, la negociación, la pluralidad, el consenso.

No sorprende, entonces, que el día de su asunción como presidente argentino, Alberto Fernández comenzara su discurso apelando a la efemérides:

El 10 de diciembre de cada año, no es un día cualquiera en nuestra memoria colectiva. Hoy celebramos el momento en que la Argentina toda sepultó la más cruel de las dictaduras que hemos debido soportar. Ese día, hace treinta y seis años, Raúl Alfonsín asumía la Presidencia, nos abría una puerta hacia el respeto a la pluralidad de ideas y nos devolvía la institucionalidad que habíamos perdido.

"Pluralidad de ideas", "institucionalidad": se oyen allí términos que habían formado parte del vocabulario del kirchnerismo y que año tras año habían sido después marginados. Néstor Kirchner había asumido su gobierno celebrando la "pluralidad" y "las verdades relativas" frente al "discurso único" del neoliberalismo. La mención de Raúl Alfonsín, ex presidente por la Unión Cívica Radical, sugiere que "la mayor amplitud posible de gobierno" es también un asunto de nombres propios, de tradiciones y de símbolos. Las memorias, como las convicciones, más vale no dejarlas en las puertas de la Casa Rosada. A veces una fuerza política encuentra su "lugar en la historia" apostando por los menos enfáticos de sus relatos.

\section{Notas}

1. Las palabras entrecomilladas, salvo indicación en contrario, remiten a las piezas comunicacionales recabadas para la investigación.

2. El sintagma está tomado de Svampa (2003). Según la autora, el ethos de los setenta "se caracterizó por la desconfianza en las vías reformistas y el desprecio por el sistema partidocrático. Su encarnación más acabada fue la figura del militante político, definido por una 'mística' revolucionaria, vale decir por un compromiso que se postulaba como permanente y radical". En otro artículo, agrega: "Las formas de acción y movilización del período eran diversas e incluían no sólo la violencia, sino las manifestaciones, las pintadas, la acción barrial, la militancia en las villas. Combinados, estos repertorios de acción irían definiendo los marcos sociales y culturales a partir de los cuales toda una nueva generación de militantes se dotó de una identidad política" (Svampa, 2002).

3. Véase al respecto Ollier (2009).

4. Sobre personalización de la política, remitimos a Le Bart (2013). 
5. Para Charaudeau, ethos de competencia significa, en efecto, "tener los medios, el poder y la experiencia para cumplir completamente con los objetivos, y obtener resultados positivos" (2006: 125).

6. Sobre la "rosca política", ver el reciente libro de Gené (2019).

7. Hablaremos indistintamente de mundo imaginal, imaginario o mundo éthico. Sabemos que cada uno de esos términos remite a tradiciones diferentes y que no son necesariamente compatibles. Sin embargo, no nos interesa ocuparnos de esa distinción en este texto. Utilizamos estas nociones para referir de manera indistinta al hecho de que todo político o fuerza política construye un mundo de imágenes, más o menos estereotipadas, más o menos conectadas con legados ideológicos, que procura generar identificación y/o credibilidad en los destinatarios. El orador, sea individual o colectivo, se ofrece como garante de esa imaginación. Véase al respecto Maingueneau (2002), Charaudeau (2006) y Lamizet (2012).

8. «Frente para la Victoria», «Unidad Ciudadana», «Frente de Todos» son diferentes nombres que tuvieron los frentes y coaliciones organizados en torno al kirchnerismo, principal electora.

9. Su papel como oposición después de la derrota en las elecciones presidenciales de 2015 podría ser leído como un tercer momento: el pasaje de oficialismo a oposición. Sin embargo, consideramos que en términos de imaginarios la mutación efectiva ocurrió en la campaña para las elecciones de 2019 y no en la campaña para las legislativas de 2017. 10. No faltó tampoco un imaginario latinoamericano. No es este, sin embargo, el lugar para desarrollar este aspecto. Véase al respecto Dagatti (2015).

11. No hay en los primeros años de gobierno ninguna referencia a la cuestión «nacional y popular». La única vez que el sintagma asoma es en una mención a un gobierno «nacional y racional». A partir de 2008, el uso de la fórmula «nacional y popular» se multiplica exponencialmente.

12. Remitimos al respecto a los trabajos de Flax (2015).

13. Los tres apartados siguientes retoman conclusiones de nuestras investigaciones previas, sintetizadas en Dagatti (2017).

14. No es difícil aventurar que el peronismo opera como una axiología nacional y popular de una enorme economía simbólica. Según James, "Hacia fines de 1950-1960 el peronismo había llegado a ser una suerte de lugar común proteico y maleable empleado para identificar a la clase trabajadora" (2005: 348).

15. El sintagma fue extraído de un discurso pronunciado por Kirchner el 3 de marzo de 2004, a menos de un años de haber asumido, en un acto de firma de convenios en la ciudad de Esperanza (Provincia de Santa Fe): "Me decía mi amigo el intendente de Esperanza que somos de partidos diferentes; no tenga ninguna duda, señor intendente, de que somos del mismo partido, del partido de la patria, de la honestidad, del trabajo, de la igualdad, de la educación, de honrar a aquellos que sudan y trabajan día a día por un nuevo país, por una nueva Argentina."

16. Para comprender a qué nos referimos con democracia liberal o liberalismo democrático, es útil consultar el reciente libro de Levitsky y Ziblatt (2018). En su estudio sobre la subjetividad democrática en la cultura política argentina, Ollier afirma que esta "hace 
suyos los valores éticos y políticos, la legitimidad del disenso, el pluralismo como principio y método, la aceptación de las reglas básicas de la convivencia social, el respeto de las diferencias y la voluntad de participación" (2009: 234).

17. Sobre la transversalidad durante el primer kirchnerismo, véase Torre (2005).

18. Remitimos a Montero (2012) y Dagatti (2017).

19. Salvo indicación en contrario, las traducciones son nuestras.

20. "Afirma Charaudeau: "El grado de competencia de un político se debe juzgar a partir de una visión de su trayectoria" (2006: 125).

21. Con una paráfrasis de los estudios de Escudero Chauvel (2007), podemos hablar de un «síndrome de permeabilidad imaginaria». En Malvinas. El gran relato, la autora utiliza la expresión «síndrome de permeabilidad de la información» para señalar cómo la casi totalidad de los contenidos de la prensa estuvieron en relación directa con el conflicto, volviendo al lector prisionero del discurso bélico. La guerra es tematizada en secciones informativas prima facie ajenas a la cuestión, por ejemplo, el fútbol o el arte.

22. Jaime Durán Barba fue el principal asesor de comunicación de Cambiemos-Pro en el período 2007-2019. Con el paso de los años, y a medida que la fuerza tuvo éxitos electorales cada vez más significativos, se convirtió en el modelo de asesor en el campo de la comunicación política en la Argentina. Por «duranbarbización» de la política se suele referir a políticos que se muestran descontracturados, que no pronuncian discursos agresivos, que utilizan escenarios bajos centrados entre el público, que convocan a "gente común" para que cuente sus pesares. En el caso de la ex presidenta, la «duranbarbización» estaría dada por mitigar la agresividad de sus discursos, por conceder entrevistas a periodistas opositores; sobre todo, por adoptar estrategias más notorias de marketing que nunca fueron su sello. Véase, como ejemplo: https://www.perfil.com/noticias/columnistas/la-duranbarbizacion-argentina.phtml

23. Alberto Fernández renunció a su cargo el 23 de julio de 2008, después de la crisis generada por la desaprobación del proyecto de ley de las retenciones agropecuarias. Massa, su reemplazante en la Jefatura de Gabinete, haría lo propio un año después, el 7 de julio de 2009.

24. Tomamos aquí como referencia a Levitsky y Ziblatt (2018).

25. De ninguna manera esta marginalización de la gestión y de la cultura democrática que señalamos debe entenderse como la afirmación de que el kirchnerismo dejó de ser democrático o dejó de ser competente. Significa, en cambio, que públicamente fue perdiendo interés, fuerza o capacidad para ostentar estas dimensiones. La imagen que los principales medios de comunicación construyeron al respecto no puede ser dejada de lado, pero tampoco las propias dinámicas de gobierno (sean conscientes o inconscientes) que el propio FpV desplegó para construir su identidad.

26. Por sistema topológico, Angenot entiende "un sistema de división de las tareas discursivas, es decir, un conjunto de discursos específicos, géneros, subgéneros, estilos e 'ideologías [...], reagrupados en "regiones" o campos [...]" (2010: 45). En el campo político de las democracias occidentales, la división topológica más conocida es la que distingue derecha e izquierda. En la Argentina, un estudio topológico de referencia -hecho fuera del marco de la teoría angenotiana- es Ostiguy (1998). 
27. Al respecto, Lamizet (2012) afirma que utopía y miedo constituyen las dos figuras por excelencia del imaginario político.

28. La coalición Cambiemos -ahora, Juntos por el Cambio- se organizó en torno a actores provenientes en su mayoría de diferentes tradiciones de la derecha argentina y de nuevos políticos y viejos empresarios, cuya extracción variaba entre ONGs, agrupaciones religiosas y empresas de variadas ramas. Su partido nuclear fue Propuesta Republicana (Pro), cuyo líder, Mauricio Macri, alcanzaría el cargo de Presidente de la Nación en 2015. El objetivo inicial de la fuerza, como señalan Vommaro, Morresi y Bellotti (2015), fue movilizar electores, ideas y recursos de grupos sociales y políticos que veían en el kirchnerismo su peor enemigo, el menor de sus beneficios o el mayor de sus males.

29. Véase Dagatti y Onofrio (2019)

30. Hablamos de lo que autores como Rosanvallon (2007) denominan "contrademocracia”. Según el autor, en su obra El buen gobierno (2015), la información y la accesibilidad se muestran como valores centrales dentro del imaginario de todo buen gobierno.

31. Hubo un marcado cambio en la estrategia de comunicación de Juntos por el Cambio después de la amplia derrota electoral en las elecciones primarias, abiertas, simultáneas y obligatorias. No entraremos aquí en ese terreno. Supone, en todo caso, otra etapa de trabajo.

32. Podría extenderse incluso a las victorias de Pro en la ciudad de Buenos Aires en 2007, 2009, 2011 y 2013. Como mencionamos en un comentario, Durán Barba estuvo detrás de cada una de ellas.

33. Trabajamos esta cuestión en Dagatti y Franco Häntzsch (2018).

34. Originalidad y resonancia no significa, por supuesto, éxito electoral. En la ciudad de Buenos Aires, los flash-mob bajo la consigna-canción "Macri ya fue...", que tuvieron un alcance extraordinario en términos de difusión y pregnancia, no menguaron la victoria electoral más contundente de Cambiemos por la Jefatura de Gobierno: 55,90\% vs. 35,07\%. 35. Aun cuando en los hechos ahora no forme parte más que de un contrafáctico, había un consenso entre las encuestadoras de que si Cristina Fernández de Kirchner hubiera sido la candidata a presidenta no podría superar un techo en torno al $40 \%$ en un eventual balotaje. Ver, por ejemplo, https://www.infobae.com/opinion/2019/03/16/elecciones2019-analizando-el-factor-cristina/

36. No puede pasar desapercibido que la tercera fuerza en términos de caudal electoral fuera el proyecto encabezado por Roberto Lavagna, ministro de Economía durante la salida de la crisis de 2001. Fue el titular de la cartera durante la presidencia interina de Eduardo Duhalde (2002-2003) y después con Néstor Kirchner (2003-2005, cuando renuncia a su cargo por diferencias con el presidente).

\section{Bibliografía}

Abélès, M. (2016). El espectáculo del poder. Buenos Aires: Prometeo.

Angenot, M. (2010). El discurso social. Los límites de lo pensable y lo decible. Buenos Aires: Siglo XXI Editores. 
Barthes, R. (2003). Mitologías. Buenos Aires: Siglo XXI Editores Argentina.

Charaudeau, P. (2006). Discurso político. San Pablo: Contexto.

Curia, W. (2010). El último peronista. ¿Quién fue realmente Néstor Kirchner? Buenos Aires: Sudamericana.

Dagatti, M. (2015). Refundar la patria. Los legados del primer kirchnerismo. En de Arnoux, E. N. y Zaccari, V. (eds.), Discurso y política en Sudamérica (pp. 165-200). Buenos Aires: Biblos.

Dagatti, M. (2017). El Partido de la Patria. Los discursos presidenciales de Néstor Kirchner. Buenos Aires: Biblos.

Dagatti, M. y Franco Häntzsch, C. (2019). Las tribulaciones del cambio. Estrategias argumentativas en el debate del balotaje presidencial argentino. Entrepalavras 9 (1), pp. 231-251. Disponible en: http://dx.doi.org/10.22168/2237-6321-11406.

Dagatti, M. y Onofrio, P. (2019). Visiones políticas. El sistema imaginario de Cambiemos (Argentina, 2015-2018). Cuaderno.info, $n^{\circ}$. 44, pp. 119-138. Disponible en: https://doi. org/10.7764/cdi.44.1628.

Escudero Chauvel, L. (2007). Malvinas: el gran relato. Fuentes y rumores en la información de guerra. Barcelona: Gedisa.

Flax, R. (2015). La caracterización de la juventud peronista en el discurso de Cristina Fernández de Kirchner. Cadernos de Linguagem e Sociedade 16 (1), pp. 61-80. Disponible en: https://doi.org/10.26512/les.v16i1.7532

Gené, M. (2019). La rosca política. El oficio de los armadores delante y detrás de escena (o el discreto encanto del toma y daca). Buenos Aires: Siglo XXI.

James, D. (2005). Resistencia e integración. El peronismo y la clase trabajadora argentina, 1946-1974. Buenos Aires: Siglo XXI.

Lamizet, B. (2012). L'imaginaire politique. Cachan: La Voisier.

Le Bart, Ch. (2013). L’égo-politique. Essai sur l'individualisation du champ politique. París: Armand Colin.

Levitsky, S. y Ziblatt, D. (2018). Cómo mueren las democracias. Buenos Aires: Ariel.

Maingueneau, D. (2002). Problèmes d'ethos. Pratiques, n. 113/114, pp. 55-67. Disponible en: www.persee.fr/doc/prati_0338-2389_2002_num_113_1_1945

Montero, A. (2012). “ $Y$ al final un día volvimos!” Los usos de la memoria en el discurso kirchnerista (2003-2007). Buenos Aires: Prometeo.

Morresi, S. (2015). 'Acá somos todos democráticos'. El PRO y las relaciones entre la derecha y la democracia en Argentina. En Vommaro, G. y Morresi, S. (orgs.). "Hagamos equipo". PRO y la construcción de la nueva derecha en la Argentina (pp. 163-201). Los Polvorines: UNGS.

Natanson, J. (2004). El presidente inesperado. El gobierno de Kirchner según los intelectuales argentinos. Rosario: Homo Sapiens.

Ollier, M. M. (2009). De la revolución a la democracia. Cambios privados, públicos y políticos de la izquierda argentina. Buenos Aires: Siglo XXI.

Ostiguy, P. (1998). Peronism and anti-Peronism: Class-cultural cleavages and political identity in Argentina. Berkeley: University of California.

Rosanvallon, P. (2007). La contrademocracia. La política en la era de la desconfianza. Buenos Aires: Manantial. 
Rosanvallon, P. (2015). El buen gobierno. Buenos Aires: Manantial.

Sadin, E. (2018). La siliconización del mundo. La irresistible expansión del liberalismo digital. Buenos Aires: Caja Negra.

Svampa, M. (2002). Las dimensiones de las nuevas protestas sociales. Disponible en: http:// www.maristellasvampa.net/archivos/ensayo29.pdf

Svampa, M. (2003). El populismo imposible y sus actores. En D. James (Dir.), Nueva historia argentina, 1955-1976 IX. Buenos Aires: Sudamericana. Disponible en: http:// maristellasvampa.net/archivos/ensayo25.pdf

Tönnies, F. (1947). Comunidad y sociedad. Buenos Aires: Losada.

Torre, J. C. (2005). La operación política de la transversalidad. El presidente Kirchner y el Partido Justicialista. En CEDIT (Comp.). Argentina en perspectiva. Reflexiones sobre nuestro país en democracia. Buenos Aires: Universidad Torcuato Di Tella.

Vommaro, G.; Morresi, S. y Bellotti, A. (2015). Mundo Pro. Anatomía de un partido fabricado para ganar. Buenos Aires: Planeta.

\begin{abstract}
Politics involve all senses: we listen to political speeches, we participate in political rituals, we attend demonstrations and protests, we follow politicians' Twitter, Facebook or Instagram accounts. Political forces deploy imaginal worlds filled with symbols, images and rituals, that invite us to follow their projects, their ideas, their values. In this article we try to understand the ethical world of the Front of Everyone [Frente de Todos] during the presidential elections of 2019. In order to do so, we take into consideration the imaginary logics deployed by Kirchnerism since its arrival to the Pink House in 2003. A hypothesis guides this text: the imaginary world of the current administration represents a mutation from the former Kirchnerist experiences. The reason for said mutation is the recovery of memories associated with democratic culture and governmental capacity, memories of values and experiences that the force itself had originally encouraged and then progressively left aside.
\end{abstract}

Keywords: imaginal world - Kirchnerism - national identity - democracy - competence.

Resumo: A política envolve todos os sentidos: escutamos, vemos e lemos discursos políticos, participamos de rituais políticos, assistimos às mobilizações e protestos, recebemos a visita de um dirigente, seguimos líderes políticos nas redes sociais. Símbolos, imagens e rituais participam dos mundos imagináveis que as diferentes forças políticas pretendem alçar como espaço de incorporação. Este artigo realiza uma interpretação do mundo ético do Frente de Todos nas eleições nacionais de 2019. Para tanto, recorre-se às lógicas imaginárias que o kirchnerismo alçou desde sua chegada ao Poder Executivo Nacional em 2003. Uma hipótese guia este texto: o mundo imaginal do atual governo representa uma mutação em relação com aquele da última década kirchnerista, porque tem recuperado memórias associadas com a cultura democrática e com a capacidade de gestão, 
memórias de valores e experiências que à força havia em sua origem impulsionado e que depois deixou progressivamente de lado.

Palavras-chave: mundo imaginal - kirchnerismo - identidade nacional - democracia competência.

[Las traducciones de los abstracts fueron supervisadas por el autor de cada artículo] 